\title{
Weichselian permafrost depth in the Netherlands: a comprehensive uncertainty and sensitivity analysis
}

\author{
Joan Govaerts ${ }^{1}$, Koen Beerten ${ }^{1}$, and Johan ten Veen ${ }^{2}$ \\ ${ }^{1} \mathrm{SCK} \cdot \mathrm{CEN}$, Institute Environment-Health-Safety, Boeretang 200, $2400 \mathrm{Mol}$, Belgium \\ ${ }^{2}$ TNO Geological Survey of the Netherlands, Princetonlaan 6, 35584 CB Utrecht, the Netherlands \\ Correspondence to: Joan Govaerts (jgovaert@sckcen.be)
}

Received: 25 February 2016 - Published in The Cryosphere Discuss.: 12 May 2016

Revised: 30 September 2016 - Accepted: 23 October 2016 - Published: 25 November 2016

\begin{abstract}
The Rupelian clay in the Netherlands is currently the subject of a feasibility study with respect to the storage of radioactive waste in the Netherlands (OPERA-project). Many features need to be considered in the assessment of the long-term evolution of the natural environment surrounding a geological waste disposal facility. One of these is permafrost development as it may have an impact on various components of the disposal system, including the natural environment (hydrogeology), the natural barrier (clay) and the engineered barrier. Determining how deep permafrost might develop in the future is desirable in order to properly address the possible impact on the various components. It is expected that periglacial conditions will reappear at some point during the next several hundred thousands of years, a typical time frame considered in geological waste disposal feasibility studies. In this study, the Weichselian glaciation is used as an analogue for future permafrost development. Permafrost depth modelling using a best estimate temperature curve of the Weichselian indicates that permafrost would reach depths between 155 and $195 \mathrm{~m}$. Without imposing a climatic gradient over the country, deepest permafrost is expected in the south due to the lower geothermal heat flux and higher average sand content of the post-Rupelian overburden. Accounting for various sources of uncertainty, such as type and impact of vegetation, snow cover, surface temperature gradients across the country, possible errors in palaeoclimate reconstructions, porosity, lithology and geothermal heat flux, stochastic calculations point out that permafrost depth during the coldest stages of a glacial cycle such as the Weichselian, for any location in the Netherlands, would be $130-210 \mathrm{~m}$ at the $2 \sigma$ level. In any case, permafrost would not reach depths greater than $270 \mathrm{~m}$. The most sensitive parameters in per-
\end{abstract}

mafrost development are the mean annual air temperatures and porosity, while the geothermal heat flux is the crucial parameter in permafrost degradation once temperatures start rising again.

\section{Introduction}

Northern hemispheric permafrost is presently restricted to areas in close proximity to the Arctic, generally north of $60^{\circ}$ north latitude, and even further to the south in mountainous areas (e.g. Himalaya, northern Rocky Mountains; Vandenberghe et al., 2014). Today, the lowlands of northwestern Europe are free of permafrost. However, palaeoclimatic reconstructions have pointed out that much of northwestern Europe experienced permafrost conditions during the last glacial maximum (LGM; Huijzer and Vandenberghe, 1998), recently also termed the last permafrost maximum (LPM; Vandenberghe et al., 2014). Notwithstanding the fact that recent studies suggest global warming to continue or accelerate during the next 100 years (Stocker et al., 2013), or that we might be facing an exceptionally long interglacial (Berger and Loutre, 2002), it is expected that periglacial conditions will reappear in northwestern Europe (e.g. Belgium and the Netherlands) at some point during the next several hundred thousands of years, a typical time frame considered in geological waste disposal studies (BIOCLIM, 2001). Whereas the distribution, type and timing of frozen ground in the past is, generally speaking, relatively well known in northwestern Europe from the distribution of shallow subsoil periglacial deformation phenomena (Huijzer and Vandenberghe, 1998), the maximum depth of past permafrost development is diffi- 
cult to observe in the geological record. Therefore, numerical simulation seems to be the most suitable tool to estimate past and future permafrost depths and has been applied already in several case studies elsewhere in Europe (Deslisle, 1998; Grassmann et al., 2010; Kitover et al., 2013; Busby et al., 2015).

Many of the countries that experienced permafrost in the past, such as the Netherlands, Belgium, United Kingdom, France and Germany, are currently running feasibility studies for the disposal of radioactive waste in deep geological repositories (Grupa, 2014). The concept of geological disposal is based on a multi-barrier system. Engineered barriers, consisting of steel components, concrete and/or bentonite are designed to contain the nuclear waste. Subsequently, the engineered barrier is placed in a natural barrier consisting of a low-permeability host rock that is situated at sufficient depth and located in a stable geological environment. Permafrost development may have an impact on various components of the disposal system, including the natural environment, the natural barrier and the engineered barrier. The hydrological cycle will completely change under permafrost conditions, up to the point where surface and subsurface hydrology become completely independent, and groundwater flow is drastically changed (Weert et al., 1997). Furthermore, landscape, vegetation and thus the biosphere will be completely different under permafrost conditions (Beerten et al., 2014). Hydraulic properties of aquifer sands and aquitard clays might be affected during permafrost conditions, especially if accompanied by repeated freeze-thaw cycles (Othman and Benson, 1993; McCauley et al., 2002). Migration of radionuclides through the host rock may be altered and the mechanical properties of the engineered barriers may be affected due to freeze-thaw cycles (Busby et al., 2015). Porewater chemistry might change due to outfreezing of salts, and gas hydrates may develop (Stotler et al., 2009). Finally, microbial activity in the host rock will likely be affected. It is thus important to determine how deep permafrost will develop in order to properly address the possible impact on the various components. Thick and deep low-permeability clay formations are often good candidates for host rocks. The $\mathrm{Ru}-$ pelian clay, which is subcropping in most of the northwestern European countries mentioned above (Vandenberghe and Mertens, 2013), is considered in the Dutch geological disposal project (Onderzoeksprogramma eindberging radioactief afval, "OPERA") as a candidate host-rock (Grupa, 2014). In the present northwestern European context it provides an interesting case study because it is distributed over a wide range of settings with respect to overburden thickness, lithology, porosity and geothermal heat flux.

Usually, uncertainties in permafrost modelling studies in the context of radioactive waste disposal are not addressed in a systematic way (e.g. Busby et al., 2015; Holmen et al., 2011; Hartikainen et al., 2010). The sensitivity of permafrost models is often assessed in terms of variations to single parameters like porosity or surface temperature one at a time
(Kitover et al., 2013). These kinds of local sensitivity analyses (SAs) assess the response of the model output to a small perturbation of single parameters, one at a time, around a nominal value. The main disadvantage of this method is that information about the sensitivity is only valid for this very specific location in the parameter space, which is usually not representative of the physically possible parameter space, and becomes problematic especially in the case of non-linear models. To overcome this problem, a global stochastic sensitivity analysis is used in this work, where multiple locations in the physically possible parameter space are evaluated at the same time.

In this paper, we will present permafrost depth calculations for a number of areas in the Netherlands that are representative for a specific geological setting using a best estimate temperature curve for a glacial cycle that is analogous to the last glacial period (Weichselian). In addition, results from stochastic simulations will be presented that give an indication of the probability of permafrost depths under a future glacial climate, taking into account various combinations of temperature, overburden lithology, porosity and geothermal heat flux. Furthermore, a sensitivity analysis is performed to identify the key model parameters that cause the uncertainty of the calculated permafrost depths. As such, the work performed in Govaerts et al. (2011), which was done for one potential site in the framework of the Belgian research programme on geological disposal, is taken a few steps further.

The results of the simulations can be used to assess if the foreseen depth of a future geological disposal facility in the Netherlands is sufficient to exclude possible adverse effects from the presence of developing permafrost. Until now, these kinds of simulations were not performed nationwide, and a more thorough uncertainty and sensitivity analysis adds to the robustness of the findings.

\section{Mathematical and numerical model for permafrost growth and degradation}

To describe heat transport in the subsurface of the Netherlands, the following one-dimensional enthalpy conservation equation is used with heat transport only occurring by conduction.

$C_{\mathrm{eq}} \frac{\partial T}{\partial t}+\nabla \cdot\left(-\lambda_{\mathrm{eq}} \nabla T\right)=Q$,

where $C_{\text {eq }}$ is the effective volumetric heat capacity $\left(\mathrm{J} \mathrm{K} \mathrm{m}^{3}\right)$, $T$ is temperature $(\mathrm{K}), \lambda_{\text {eq }}$ is the effective thermal conductivity $\left(\mathrm{W}(\mathrm{m} \mathrm{K})^{-1}\right)$ and $Q$ is a heat source $\left(\mathrm{W} \mathrm{m}^{-3}\right)$.

When modelling the thermal effects of freezing and thawing, Eq. (1) has to include three phases: rock matrix, fluid 
and ice. To achieve this, the following volume fractions are defined:

$\theta_{\mathrm{m}}=1-\theta \theta_{\mathrm{f}}=\theta \cdot \Theta, \theta_{\mathrm{i}}=\theta-\theta_{\mathrm{f}}$.

The subscripts $\mathrm{f}, \mathrm{i}$ and $\mathrm{m}$ account for the mixture between solid rock matrix (m), fluid-filled pore space (f) and icefilled pore space (i). This mixture is characterized by porosity $\theta$, and $\Theta$ denotes the fraction of pore space occupied by fluid. As a result of the complicated processes in the porous medium, thawing cannot be considered as a simple discontinuity. $\Theta$ is generally assumed to be a continuous function of temperature in a specified interval.

When a material changes phase, for instance from solid to liquid, energy is added to the solid. This energy is the latent heat of phase change. Instead of creating a temperature rise, the energy alters the material's molecular structure. This latent heat of freezing and melting water, $L$, is $333.6 \mathrm{~kJ} \mathrm{~kg}^{-1}$ (Mottaghy and Rath, 2006). $C_{\mathrm{eq}}$ is a volume average, which also accounts for the latent heat of fusion:

$$
\begin{aligned}
C_{\text {eq }} & =\theta_{\mathrm{m}} \rho_{\mathrm{m}} c_{\mathrm{m}}+\theta_{\mathrm{f}} \rho_{\mathrm{f}}\left(c_{f}+\frac{\partial \Theta}{\partial T} L\right) \\
& +\theta_{\mathrm{i}} \rho_{\mathrm{i}}\left(c_{\mathrm{i}}+\frac{\partial \Theta}{\partial T} L\right),
\end{aligned}
$$

where $\theta$ is the volumetric content, $\rho$ equals density $\left(\mathrm{kg} \mathrm{m}^{3}\right)$, and $\mathrm{C}$ is the specific heat capacity $\left(\mathrm{J}\left(\mathrm{K} \mathrm{kg}^{-1}\right)\right.$. It includes additional energy sources and sinks due to freezing and melting using the latent heat of fusion $L$ for only the normalized pulse around a temperature transition $\frac{\partial \Theta}{\partial T}\left(\mathrm{~K}^{-1}\right)$. The integral of $\frac{\partial \Theta}{\partial T}$ must equal unity to satisfy the condition that pulse width denotes the range between the liquidus (thawing) and solidus (freezing) temperatures of the porous soil. During cooling, solidus is that temperature at which most of the pore water of the soil is frozen. Between the solidus and liquidus temperatures, there will be a mixture of solid and liquid water phases within the soil matrix. Just below the liquidus temperature, there will be mostly liquid water phases. This approach is similar to the one used by Mottaghy and Rath (2006), Bense et al. (2009), Noetzli and Gruber (2009), Holmén et al. (2011) and Kitover et al. (2013). Values for the porosity, density and specific heat of the different components are given in Table 1.

The values of the specific heat of the Boom Clay matrix are obtained from Cheng et al. (2010). The equivalent, massbased heat capacity then adds up to 1443 and $981 \mathrm{~J}(\mathrm{~kg} \mathrm{~K})^{-1}$ for the fully unfrozen and frozen states respectively, obtained by using Eq. (3) and dividing by the bulk density of Boom Clay. This is in the same range as the values used in Marivoet and Bonne (1988) and Kömle et al. (2007) for clay sediments. The value of the sand matrix is set to a value inside the ranges that are found for quartz minerals and sands (see Mallants, 2006 and references therein). For sandy soils, the
Table 1. Properties of the different components of the subsoil

\begin{tabular}{lrrrr}
\hline Parameter & Water & Ice & Clay matrix & Sand matrix \\
\hline Density $\left[\mathrm{kg} \mathrm{m}^{-3}\right]$ & 997 & 918 & 2803 & 2358 \\
Porosity & - & - & 0.39 & Variable \\
Specific heat & 4185 & 1835 & 820 & 800 \\
{$\left[\mathrm{~J}(\mathrm{~kg} \mathrm{~K})^{-1}\right]$} & & & & \\
Thermal conductivity & 0.54 & 2.37 & $1.98^{*}$ & 3.00 \\
{$\left[\mathrm{~W}(\mathrm{~m} \mathrm{~K})^{-1}\right]$} & & & & \\
\hline
\end{tabular}

* This value has been chosen so the effective thermal conductivity equals $1.31 \mathrm{~J}(\mathrm{~kg} \mathrm{~K})^{-1}$, which is the vertical thermal conductivity of Boom Clay obtained during the ATLAS study (Chen et al., 2010).

equivalent heat capacity adds up to 1319 and $937 \mathrm{~J}(\mathrm{~kg} \mathrm{~K})^{-1}$ for the fully unfrozen and frozen states respectively when a porosity of $30 \%$ is assumed.

In case of phase change at a single temperature, thermal conductivity is not continuous with respect to temperature. However, considering the freezing range in rocks, we use Eqs. (2) and (4) for taking into account the contributions of the fluid and ice phases. Since the materials are assumed to be randomly distributed, the weighting between them is realized by the square-root mean, which is believed to have a greater physical basis than the geometric mean (Roy et al., 1981).

$\lambda_{\text {eq }}=\left(\theta_{\mathrm{m}} \sqrt{\lambda_{\mathrm{m}}}+\theta_{\mathrm{f}} \sqrt{\lambda_{\mathrm{f}}}+\theta_{\mathrm{i}} \sqrt{\lambda_{\mathrm{i}}}\right)^{2}$

Values for the thermal conductivity of the different components are given in Table 1.

The values of the thermal conductivity of the rock matrix of Boom Clay and sand are chosen in the same range of the values used by Bense et al. (2009) and Mottaghy and Rath (2006), who used respectively 4.0 and $2.9 \mathrm{~W}(\mathrm{~m} \mathrm{~K})^{-1}$ for a generic sediment rock species.

For Boom Clay, the equivalent thermal conductivity then adds up to 1.31 and $2.03 \mathrm{~W}(\mathrm{~m} \mathrm{~K})^{-1}$ for fully unfrozen and frozen states respectively. The conductivity value of unfrozen Boom Clay is thus equal to the vertical conductivity obtained from the ATLAS 3 study (Cheng et al., 2010).

In sandy soils, the equivalent thermal conductivity is 2.05 and $2.80 \mathrm{~W}(\mathrm{~m} \mathrm{~K})^{-1}$ for the fully unfrozen and frozen state respectively. The values are in the same range as the values found in Mallants (2006) and the references therein.

The heat transport equation is implemented in COMSOL Multiphysics' Earth Science Module (2008), together with all the correlations for the thermal properties. Because the thermal properties differ between the frozen and unfrozen state, a variable $\Theta$ is created, which goes from unity to zero for fully unfrozen to frozen. Therefore, the effective properties switch with the phase through multiplication with $\Theta$. The switch in $\Theta$ from 0 to 1 occurs over the liquid-to-solid interval $\left(0.0\right.$ to $\left.-0.5^{\circ} \mathrm{C}\right)$ using a fifth order $S$-shaped polynomial form (available in COMSOL as the built-in function flc $2 \mathrm{hs}$ ). The polynomial form is a smoothed Heaviside func- 
tion with a continuous second derivative without overshoot and takes on a value between 0 and 1 . As such, in this model representation, the freezing process is determined only by the change in temperature. The dependency of the freezing point of water on pressure, salinity and the adsorptive and capillary properties of the soil is not taken into account in the present calculations.

Moreover, the freezing process is modelled using a gradual and not a sudden uptake and release of the latent energy, starting at $0^{\circ} \mathrm{C}$ to ensure numerical stability. Ideally, this freezing interval should be kept as small as possible. However, decreasing the size of the interval will increase the computational burden and compromise the numerical stability. The effect of the size of the freezing interval on the permafrost depth was previously investigated by Govaerts et al. (2011, Appendix A). It was shown that there is little influence on the resulting temperature profiles as the $50 \%$ frozen isoline (which corresponds to the centre temperature value of the liquid-solid interval) is nearly identical for all the values that have been tested in that study. The size of the liquid-tosolid temperature interval does not seem to have a significant impact on the retardation of the cold wave, a phenomenon also known as the zero curtain effect. In this study, the $0{ }^{\circ} \mathrm{C}$ isotherm, which corresponds to the $0 \%$ frozen state, is used as the metric for permafrost depth.

\subsection{Parameters, initial and boundary conditions used in the reference calculation}

Permafrost development is dependent on atmospheric and surface boundary conditions, mostly air temperature and vegetation, and subsurface properties such as lithology, porosity and geothermal heat flux. As such, it is the result of interactions between global changes (temperature) and local conditions (geology). The strategy adopted for this specific study consists of the following elements. First, we try to simulate a future glacial climate using the Weichselian glaciation $(115-11 \mathrm{ka})$ as an analogue. Various temperature estimates are available for this glacial period, many of them being derived from palaeoclimatological archives in Belgium and the Netherlands. The forcing temperature is allowed to change temporally at the upper boundary but held spatially uniform for a given time step. Subsequently it will be used to force the permafrost model, which is fragmented into different representative polygons. The initial condition of the model is the steady state temperature profile based on the present day temperature gradient.

The thickness of subsurface units and their lithofacies distribution are considered relevant for permafrost modelling as this affects porosity and the effective thermal properties. The selection of the different areas for permafrost modelling is based on the presence of 17 structural elements, including six highs, five basins and six platforms (Fig. 1). The rationale is that these structural elements delineate differences in thickness and depths of both Mesozoic and Ceno-

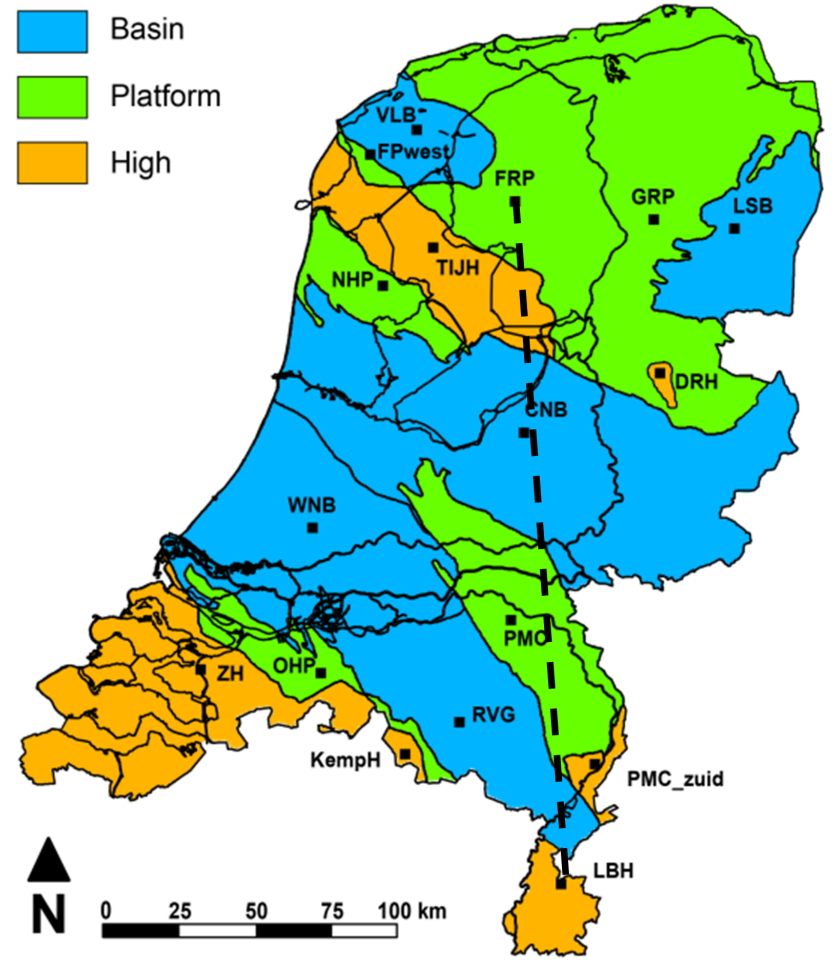

Figure 1. Structural elements in the Dutch subsurface. $\mathrm{LBH}=$ Limburg High, $\mathrm{RVG}=\mathrm{Ruhr}$ Valley Graben, $\mathrm{KempH}=$ Kempisch High, $\mathrm{ZH}=$ Zeeland High, OHP = Oosterhout Platform, $\quad$ PMC $=$ Peel-Maasbommel, $\quad$ PMC_zuid = PeelMaasbommel High, $\mathrm{WNB}=$ West Netherlands Basin, $\mathrm{CNB}=$ Central Netherlands Basin, $\mathrm{DRH}=$ Drenthe High, NHP $=$ Noord Holland Platform, TIJH = Texel-IJsselmeer High, $\mathrm{FRP}=$ Friesland Platform, FP (west) = Friesland Platform, VLB $=$ Vlieland Basin, GRP $=$ Groningen Platform, LSB $=$ Lower Saxony Basin. Dashed line refers to the profile shown in Fig. 7.

zoic subsurface units. Subsequently, a geological (property) model was constructed based on the surfaces of the deep geological model (DGM) shallow subsurface model. For each unit, vertical grid cells with a surface of $250 \mathrm{~m} \times 250 \mathrm{~m}$ and a height equal to the thickness of the unit were constructed. These grid cells were populated with the parameters described before. Subsequently, all parameters were averaged over the vertical interval overlying the Rupel Formation (the overburden). The research area is subdivided into several polygons with dimensions ranging roughly between $9 \mathrm{~km} \times 15 \mathrm{~km}$ and $110 \mathrm{~km} \times 140 \mathrm{~km}$. The midpoint positions of the various polygons are plotted in Fig. 1 .

The reference calculation consists of 17 simulations of permafrost progradation and degradation during the last interglacial-glacial-interglacial cycle. Each calculation is performed for one of the 17 polygons. These are discussed in more detail in the following section. It should be noted that this method does not allow for local variations to be in- 

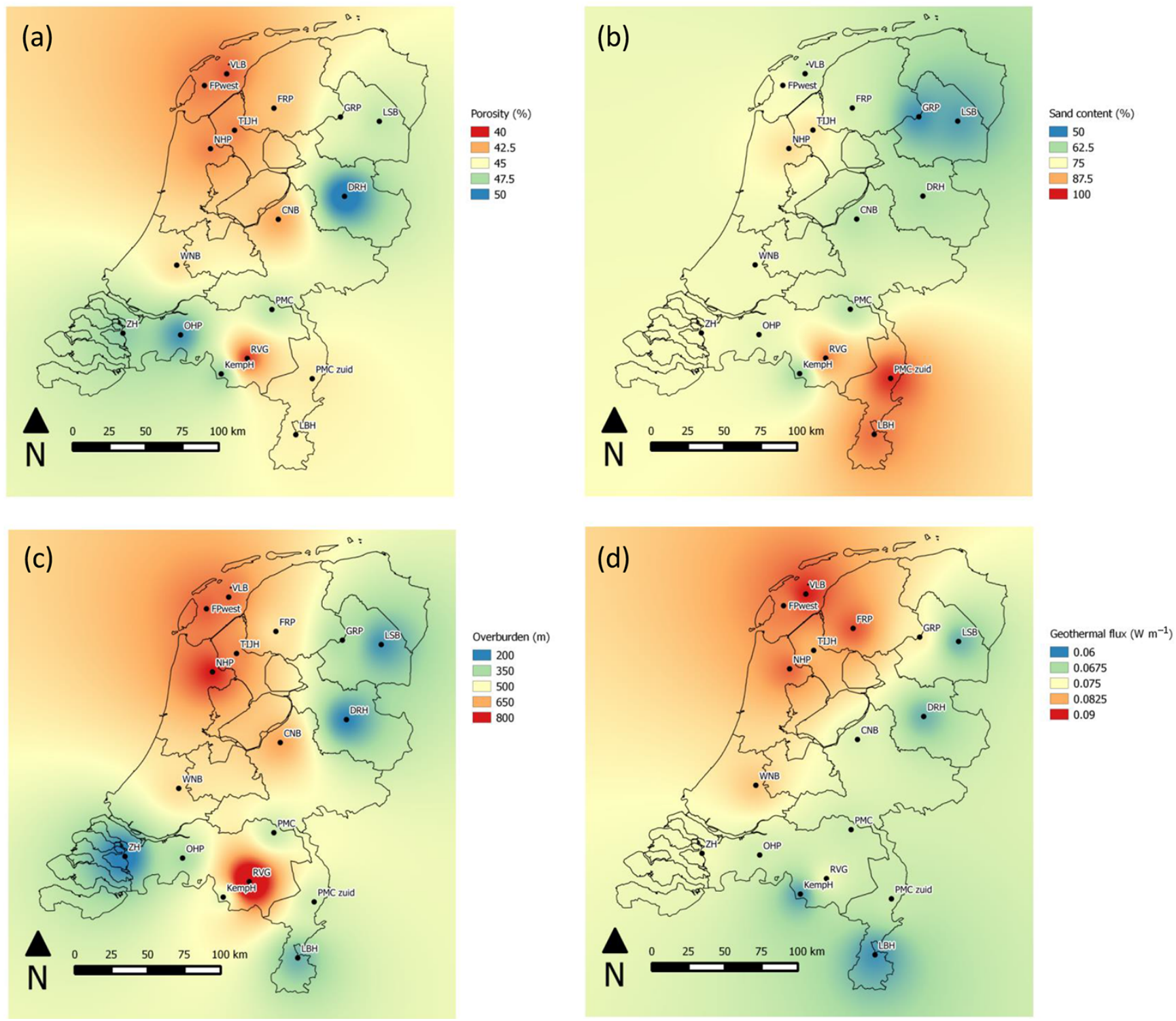

Figure 2. (a) Averaged mid-depth porosity variability of the post-Rupelian overburden, (b) distribution of the average sand content in the post-Rupelian overburden, (c) depth of the top of the Rupel Formation, also representing the thickness of the overburden (m), (d) spatial distribution of geothermal heat flux values $\left(\mathrm{W} \mathrm{m}^{3}\right)$. The flux is significantly higher in the (north)west than the (south)east of the country.

cluded, but rather serves to highlight regional trends over the Netherlands.

\subsection{Porosity, lithology and overburden thickness}

An important parameter for permafrost modelling is porosity. Porosity is directly linked with water content as full saturation is assumed. Consequently, thermal conductivity and the equivalent heat capacity of the soil correspond with these conditions (see Table 1 and Eq. 3). A porosity value is assigned to each of the lithostratigraphic units defined in the Digital Geological Model (DGM; Gunnink et al., 2013) of the shallow Dutch subsurface. The hydrogeological model
REGIS (Vernes and van Doorn, 2005) provides a further subdivision and includes both aquifers (sand) and non-aquifer layers (clay). Using the REGIS information a percentage of clay vs. sand for each of the DGM units can be calculated. Based on a relatively small number of porosity measurements of the sand and clay layers in the stratigraphic interval above the Rupel Formation, a best fit, generally applicable porosity-depth relationship was established for all sandy and clayey depositional facies of the various units. This allows for making porosity predictions in non-studied domains.

Several trends can be observed from Fig. 2. The highest averaged mid-depth porosities for the post-Rupelian overburden are observed in the east and the southwest, reaching 
$50 \%$. The lowest values are found in the southeast (Ruhr Valley Graben, polygon RVG) and the northwest. The porosity is influenced by two other parameters: lithology and burial depth. The thicker the post-Rupelian overburden, the deeper the mid-depth for which the porosity is determined, and thus the lower the porosity. Lithology also has an influence on porosity because on average, clay has a higher porosity than sand. As such, the porosity map is a mirror image of a combination of lithology and overburden thickness. Note that the depth to the top of the Rupel Formation is representative for the total overburden depth, which is strongly coupled to the tectonic setting, i.e. thick in basins and grabens and relatively thin on structural highs (Figs. 1 and 2). Lithofacies (given as sand percentage) seem to be linked to certain structural elements. Notably in the southeastern Netherlands, the sand content is very high, reaching more than $80 \%$ in the RVG and adjacent areas. These areas acted as traps for a thick series of Neogene continental sands.

\subsection{Upper boundary condition: temperature evolution of a future glacial cycle}

The temperature curves and data used in this study are shown in Fig. 3. Best estimates for the mean annual air temperature (MAAT) during MIS5 (marine isotope stage 5) are based on pollen data from van Gijssel (1995), but replotted against a more recent chronostratigraphic framework for the Weichselian glaciation (see e.g. Busschers et al., 2007). The main features of the MIS5 climate are the relatively mild stadials $5 \mathrm{~b}$ and $5 \mathrm{~d}$, with a MAAT of $-2{ }^{\circ} \mathrm{C}$, and the relatively cold interstadials $5 \mathrm{c}$ and $5 \mathrm{a}$, with a MAAT of $+4^{\circ} \mathrm{C}$. The first period with continuous permafrost development in the Netherlands would have been MIS4, with MAAT values dropping to as low as $-4^{\circ} \mathrm{C}$ (threshold for discontinuous permafrost) and even $-8^{\circ} \mathrm{C}$ (threshold for continuous permafrost) for the end of MIS4. These values are based on periglacial deformation phenomena (e.g. ice-wedge casts and large-scale involutions) in the shallow subsoil and their present-day distribution in areas of stable continuous permafrost (Vandenberghe and Pissart, 1993; Huijzer and Vandenberghe, 1998; Vandenberghe et al., 2014). The following MIS3 is characterized by a somewhat milder climate, showing less periglacial deformation of the subsoil. Analysis of flora and fauna preserved within MIS3 sediments, and the type and nature of periglacial deformation shows that some interstadials might have reached a MAAT between 0 and $+6^{\circ} \mathrm{C}$ (e.g. Upton Warren, Hengelo and Denekamp interstadials; Huijzer and Vandenberghe, 1998; Busschers et al., 2007; van Gijssel, 1995), and several stadials would have reached an MAAT as low as $-4^{\circ} \mathrm{C}$ (e.g. Hasselo stadial; Busschers et al., 2007). Subsequently, the climate evolves towards the Late Glacial Maximum (LGM), which is situated in MIS2. Data for this stage are mainly derived from Renssen and Vandenberghe (2003) and Buylaert et al. (2008) and are based on the presence and type of periglacial deformation phenomena. The MAAT for the
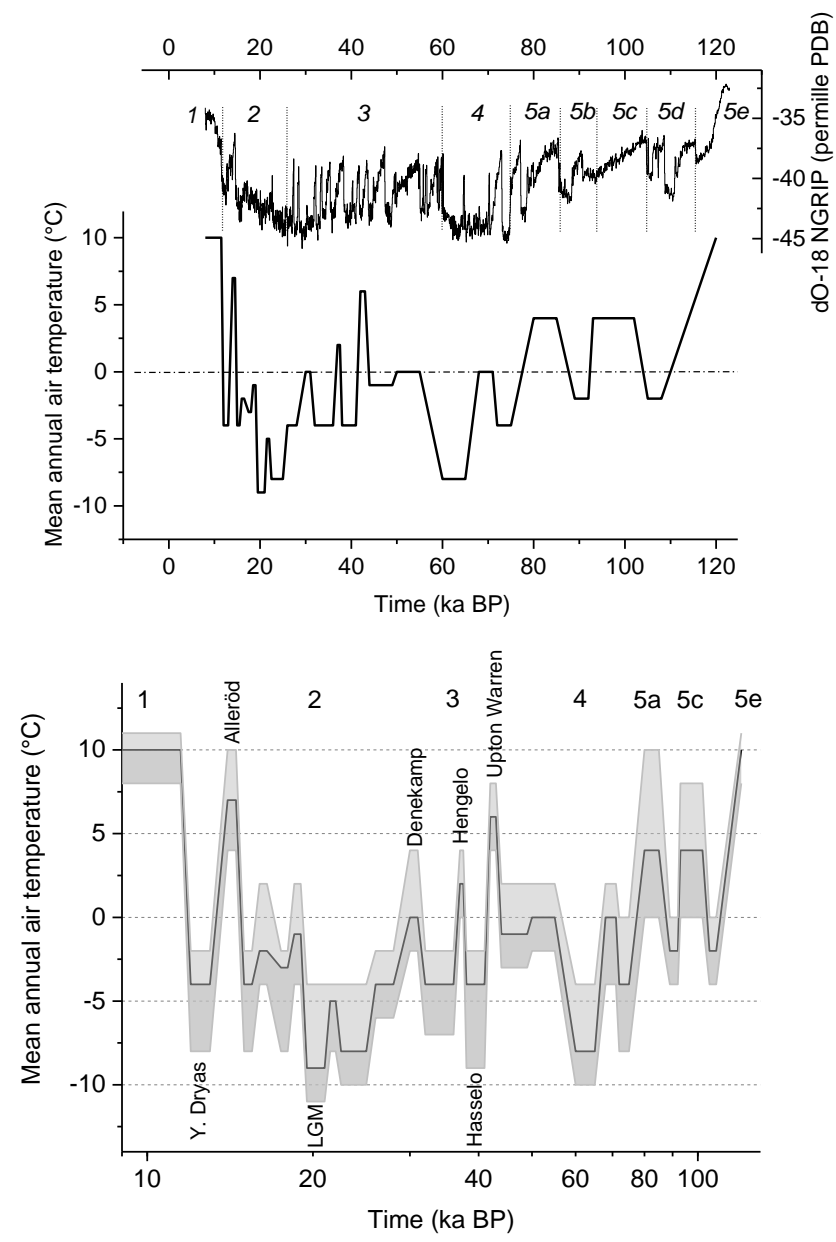

Figure 3. Top: best estimate temperature evolution for the Weichselian glaciation, which is taken as an analogue for a future glacial climate in permafrost calculations. The curve is based on data from van Gijssel (1995), Huijzer and Vandenberghe (1998), Renssen and Vandenberghe (2003), Busschers et al. (2007) and Buylaert et al. (2008). Marine isotope stages (numbering 1 to $5 \mathrm{e}$ ) are taken from Busschers et al. (2007) and references therein. The oxygen isotope curve is reproduced from the North Greenland Ice Core Project (NGRIP) (2004) data. Bottom: upper and lower bound values for stochastic permafrost calculations on a logarithmic timescale. MIS5e is equivalent to the Eemian interglacial, while MIS1 corresponds to the Holocene (present interglacial). Y. Dryas $=$ Younger Dryas.

period between 28 and $15 \mathrm{ka}$ would not have exceeded $0^{\circ} \mathrm{C}$, while some periods show MAAT values as low as $-8^{\circ} \mathrm{C}$. The end of MIS2 is characterized by a stepwise trend towards global warming, showing significant variations between interstadials (Alleröd) and stadials (Younger Dryas). Finally, present-day MAAT values of around $+10^{\circ} \mathrm{C}$ are attributed to MIS1.

Upper and lower bounds for these temperature data are given in Fig. 3. They serve as input for the permafrost depth uncertainty analysis. Instead of using one best esti- 
mate temperature evolution for the Weichselian glaciation used as an analogue, a minimum and maximum temperature distribution for each time frame is determined, which will be randomly sampled to produce various combinations of upper and lower bound MAAT values in the stochastic uncertainty analyses. Different sources of uncertainty are thus taken into account, such as the reliability of the palaeotemperature proxy, the transferability towards a future glacial climatic cycle, temperature gradients across the country and atmosphere-soil temperature coupling. Lower bound estimates are set ca. $3-4{ }^{\circ} \mathrm{C}$ lower than the best estimate. This range allows for uncertainty with respect to the palaeotemperature proxy in the case of discontinuous permafrost, which might exist up to MAAT values as low as $-8^{\circ} \mathrm{C}$ before it turns into continuous permafrost (Huijzer and Vandenberghe, 1998). For the coldest periods, such as the LGM, the lower bound MAAT was set to -11 or $21^{\circ} \mathrm{C}$ below the present day MAAT. This allows the possibility of a future glacial colder than the Weichselian analogue (e.g. the Saalian, when the Fennoscandian ice-sheet margin reached the Netherlands; Svendsen et al., 2004). Furthermore, a $21{ }^{\circ} \mathrm{C}$ temperature drop for the LGM is in line with the coldest estimate reconstructions for low lying areas in Great Britain (Busby et al., 2015). As a result, the MAAT remains below $0{ }^{\circ} \mathrm{C}$ throughout much of the glacial cycle, except for several short interstadials, such as the Alleröd.

The upper bound is based on a warm reconstruction of the Weichselian climate, which is based on a pollen sequence in sediments from the crater lake at La Grande Pile, situated ca. $500 \mathrm{~km}$ south of Amsterdam at an altitude of ca. $350 \mathrm{~m}$ (Guiot et al., 1989). The mean MAAT estimate obtained in that study is used here as an absolute maximum scenario for the Weichselian glaciation in northwestern Europe given its location. The upper bound for the time period around $20 \mathrm{ka}$, for which the pollen record gives no solution, is set to $-4{ }^{\circ} \mathrm{C}$ (or $14{ }^{\circ} \mathrm{C}$ below the present-day MAAT), because we assume that at least discontinuous permafrost would have developed in northwestern Europe around that time period. This value is slightly lower than globally reconstructed temperatures for the LGM in northwestern Europe as proposed by Annan and Hargreaves (2013) using climate modelling and proxy data.

The temperature data presented here are directly used as soil surface temperature data. However, vegetation, snow or ice would act as a shield against penetration of cold air and hamper the evolution of permafrost with depth. The effect of vegetation and snow can be addressed using the concept of freezing and thawing $n$ factors, which are equal to 1 in the case of no vegetation or snow and gradually decrease with vegetation type and snow thickness (Lunardini, 1978). During a Weichselian glacial cycle as the one presented here, the shielding effect of snow would increase the mean annual soil surface temperature (MAST) by 2 to $5^{\circ} \mathrm{C}$ with respect to the MAAT (northern Belgium; Govaerts et al., 2011). Departing from the best estimate temperature curve, this range is almost entirely covered by the uncertainty range (Fig. 3).
It has to be mentioned that the model neglects subsurface hydrology such as the vadose zone and groundwater flow. During very cold stadials, infiltration would probably be so low that the groundwater table would be significantly lower. Unsaturated soil slows down permafrost development because of the difference in thermal conductivity between air and water. Full saturation of the pore space is adopted in the present calculations, aiming at keeping the model conservative with respect to neglected processes. Next, groundwater flow is neglected but it is evident that this would slow down the speed of permafrost development as well because of the redistribution of heat (Kurylyk et al., 2014). Finally, outfreezing of pore water salt would lower the speed of permafrost development because more heat needs to be extracted to freeze water with elevated salt concentrations (Stotler et al., 2009).

\subsection{Lower boundary condition: geothermal heat flux}

For each of the 17 polygons, the mid-depth temperature and the surface temperature were used to calculate the temperature gradient. These data are then used to calculate the geothermal heat flux using the averaged thermal conductivity values of the sandy overburden (Fig. 2d). Generally speaking, the country is split up between a southeastern part with lower values of the geothermal heat flux (0.06$0.07 \mathrm{~W} \mathrm{~m}^{-3}$ ) and a northwestern part with higher flux values (up to $0.09 \mathrm{~W} \mathrm{~m}^{-3}$ ). It is interesting to note that this pattern follows the pattern of recent differential tectonic land movement as calculated by Kooi et al. (1998). The higher flux values in the northwest can also be linked to higher mid-depth temperatures in that area. These in turn are the result of the presence of Zechstein salt layers that have a relatively high thermal conductivity (ca. $4 \mathrm{~W}(\mathrm{~m} \mathrm{~K})^{-1}$; Bonté et al., 2012).

\subsection{Model domain, boundary conditions and computational settings}

The upper part of the one-dimensional domain is modelled as sandy soil for each of the 17 polygons as deep as the overburden reaches. The total vertical length of the one-dimensional lithological domain is then extended to at least $500 \mathrm{~m}$ with clay material, in case the overburden does not reach this depth. This implies assuming that the Rupelian layers underlying the overburden are sufficiently thick to bridge the distance from the bottom of the overburden to a depth of $500 \mathrm{~m}$. The lower boundary condition needs to be imposed at a distance sufficiently far from the top to avoid artificial, numerical interaction with the surface temperature boundary condition. This is illustrated, together with the boundary conditions, in Fig. 4. Material parameters are held constant along the domain length for each soil type.

Due to the 1-D nature of the model, mesh size poses no strong obstacle. The results are checked for grid independency by systematically refining the mesh. As a result, a 


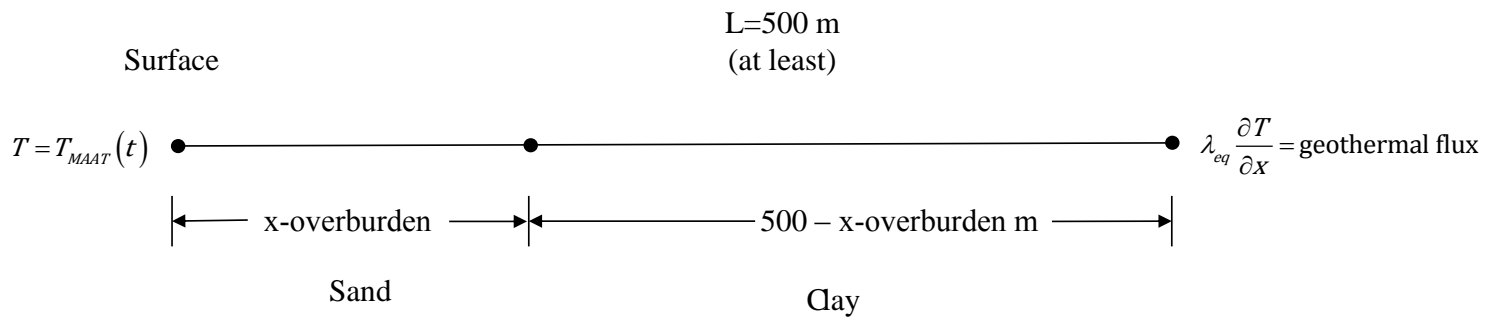

Figure 4. Model domain and boundary conditions.

mesh of 500 equidistant elements is chosen as an optimal setting for the final simulations. Absolute and relative tolerances for convergence within each timestep are set to 1e-4. The COMSOL software adapts the size of the timestep in order to fulfill this requirement.

\subsection{Stochastic uncertainty and sensitivity analysis}

\subsubsection{Uncertainty analysis}

As an integral part of a safety case file, supporting calculations for radioactive waste disposal often involves the analysis of complex systems. Various types of uncertainty affect the results of the evaluations. An overview of the treatment of uncertainties in the disposal programmes of several European countries has been compiled within the PAMINA project (Marivoet et al., 2008).

The nature of the uncertainty can be stochastic (or aleatory) or subjective (or epistemic). Epistemic uncertainty derives from a lack of knowledge about the adequate value for a parameter, input or quantity that is assumed to be constant throughout model analysis. In contrast, a stochastic model will not produce the same output when repeated with the same inputs because of inherent randomness in the behaviour of the system. This type of uncertainty is termed aleatory or stochastic.

In general a distinction is made between three sources of uncertainty: uncertainty in scenario descriptions, including the evolution of the main components of the repository system; uncertainty in conceptual models; uncertainty in parameter values.

Although both types and even sources of uncertainties cannot be entirely separated, the work in this report deals mostly with subjective (or epistemic) uncertainties, which are reflected in the uncertainties in parameter values.

Parameters, initial and boundary conditions for mathematical models are seldom known with a high degree of certainty. The study of parameter uncertainty is usually subdivided into two closely related activities referred to here as uncertainty analysis and sensitivity analysis, where (i) uncertainty analysis (UA) involves the determination of the uncertainty in analysis results that derive from uncertainty in input parameters and (ii) sensitivity analysis (SA) involves the determination of relationships between the uncertainty in analysis results and the uncertainty in individual analysis input parameters. SA identifies the parameters for which the greatest reduction in uncertainty or variation in model output can be obtained if the correct value of this parameter could be determined more precisely.

To this end, a Monte Carlo simulation is based on performing multiple model evaluations using random or pseudorandom numbers to sample from probability distributions of model inputs. The results of these evaluations can be used to both determine the uncertainty in model output and perform SA. The popular and robust Monte Carlo (MC) method in combination with the efficient Latin hypercube sampling (LHS) is used here and is described in several review papers and textbooks (e.g. Marino et al., 2008; Helton, 1993). LHS requires fewer samples than simple random sampling and achieves the same level of accuracy.

\subsubsection{Implementation}

The calculations are done in three steps, using MATLAB 2012a (MathWorks) linked to the finite element PDE solver Comsol 3.5a (2008). First, values of all selected stochastic input variables are sampled for all the runs using built-in MATLAB functions. All variables are assumed to be independent so no in-between correlations were implemented. A number of simulations are then performed using the sampled parameter combinations. MATLAB was used to automate the simulations performed by the FE code COMSOL for all Monte Carlo runs. Tables of collected results produced by MATLAB can then be directly analysed to calculate and plot the percentiles and mean value of the permafrost depth as a function of time. MATLAB was then used again to compute standardized or partial correlation coefficients to investigate the parameter sensitivity. For the regression-based analyses, 1000 realizations are performed to obtain the results for each scenario. In order to guarantee stability of the output, enough realizations should be provided. The minimum number of realizations required to assure stable output depends on the system itself and the number of uncertain variables associated with it. Helton (2005) showed that 100-300 model runs were sufficient for stable results using a far more complex two-phase flow model with 37 uncertain variables. 
Table 2. Parameters and associated ranges used in the global UA and SA., T1 to T26, are used to control the magnitude of the various temperature plateaus during the Weichselian temperature cycle (Fig. 3), ranging from $-11^{\circ} \mathrm{C}$ for the lowest and $+11^{\circ} \mathrm{C}$ for the highest.

\begin{tabular}{lrrrr}
\hline Parameter & Minimum & Maximum & Mode & Simulation time frame (ka) \\
\hline Porosity [-] & 0.2 & 0.7 & 0.45 & All \\
Fraction of sand [-] & 0.1 & 1 & 0.75 & All \\
Geothermal heat flux [W m $\left.^{-3}\right]$ & 0.033 & 0.115 & 0.060 & All \\
Overburden thickness [m] & 20 & 1500 & 500 & All \\
Initial temperature gradient $\left[\mathrm{K} \mathrm{m}^{-1}\right]$ & 0.022 & 0.033 & 0.028 & Initial condition \\
T1 [K] & 281.15 & 284.15 & 283.15 & $0-11.5$ \\
T2 [K] & 269.15 & 273.15 & 271.15 & $12-13$ \\
T3 [K] & 273.15 & 281.15 & 277.15 & $14-14.5$ \\
T4 [K] & 269.15 & 273.15 & 271.15 & $15-15.5$ \\
T5 [K] & 273.15 & 283.15 & 277.15 & $16-16.5$ \\
T6 [K] & 265.15 & 273.15 & 269.15 & $17.5-18$ \\
T7 [K] & 269.15 & 275.15 & 273.15 & $18.5-19$ \\
T8 [K] & 263.15 & 269.15 & 265.15 & $19.5-21$ \\
T9 [K] & 271.15 & 275.15 & 273.15 & $21.5-22$ \\
T10 [K] & 270.15 & 275.15 & 272.15 & $22.5-25$ \\
T11 [K] & 277.15 & 281.15 & 279.15 & $26-28$ \\
T12 [K] & 264.15 & 271.15 & 269.15 & $30-31$ \\
T13 [K] & 273.15 & 277.15 & 275.15 & $32-36$ \\
T14 [K] & 266.15 & 271.15 & 269.15 & $37-37.5$ \\
T15 [K] & 271.15 & 277.15 & 273.15 & $38-41$ \\
T16 [K] & 267.15 & 271.15 & 269.15 & $42-43$ \\
T17 [K] & 263.15 & 269.15 & 265.15 & $44-49$ \\
T18 [K] & 265.15 & 269.15 & 268.15 & $50-55$ \\
T19[K] & 262.15 & 269.15 & 264.15 & $60-65$ \\
T20 [K] & 269.15 & 275.15 & 272.15 & $68-71$ \\
T21 [K] & 265.15 & 271.15 & 270.15 & $72-75$ \\
T22 [K] & 269.15 & 275.15 & 271.15 & $80-85$ \\
T23 [K] & 265.15 & 271.15 & 269.15 & $89-92$ \\
T24 [K] & 277.15 & 283.15 & 280.15 & $93-102$ \\
T25 [K] & 265.15 & 271.15 & 269.15 & $105-108$ \\
T26 [K] & 281.15 & 284.15 & 283.15 & 120 \\
\hline & & & &
\end{tabular}

\subsubsection{Parameter Ranges}

The stochastic simulations give an indication of the probability of nationwide permafrost depths under a future glacial climate, taking into account various combinations of temperature, overburden lithology, porosity and geothermal heat flux.

A proper quantification of uncertainties in the form of probability density functions (PDFs) is an essential part of the uncertainty management and a prerequisite for probabilistic uncertainty and sensitivity analysis. As the actual knowledge about the statistical distribution of the parameters in question is limited, it is only possible to estimate a minimum, a maximum and a most probable value. In this case the triangular distribution is the most appropriate expression of the state of the knowledge (Bolado et al., 2009).

The parameters that are investigated in the stochastic analysis are shown in Table 2. Their minimum, maximum and mode values are used to build a triangular probability density function, which is sampled in the stochastic analysis. T1 to T26 are variables that are used to control the magnitude of the various temperature plateaus during the Weichselian temperature cycle. This allows to account for the actual parameter uncertainty for temperature as well as nationwide spatial parameter variability.

\subsubsection{Sensitivity analysis}

A wide range of SA methods exists but can generally be classified into Local and Global techniques. Local SA will be assessing the response of the model output to a small perturbation of single parameters (the so called one at a time method) around a nominal value. The main disadvantage of this method is that information about the sensitivity is only valid for this very specific location in the parameter space only, which is usually not representative of the physically possible parameter space, which becomes problematic especially in the case of non-linear models.

To deal with this problem global SA methods have been developed, where multiple locations in the physically possi- 

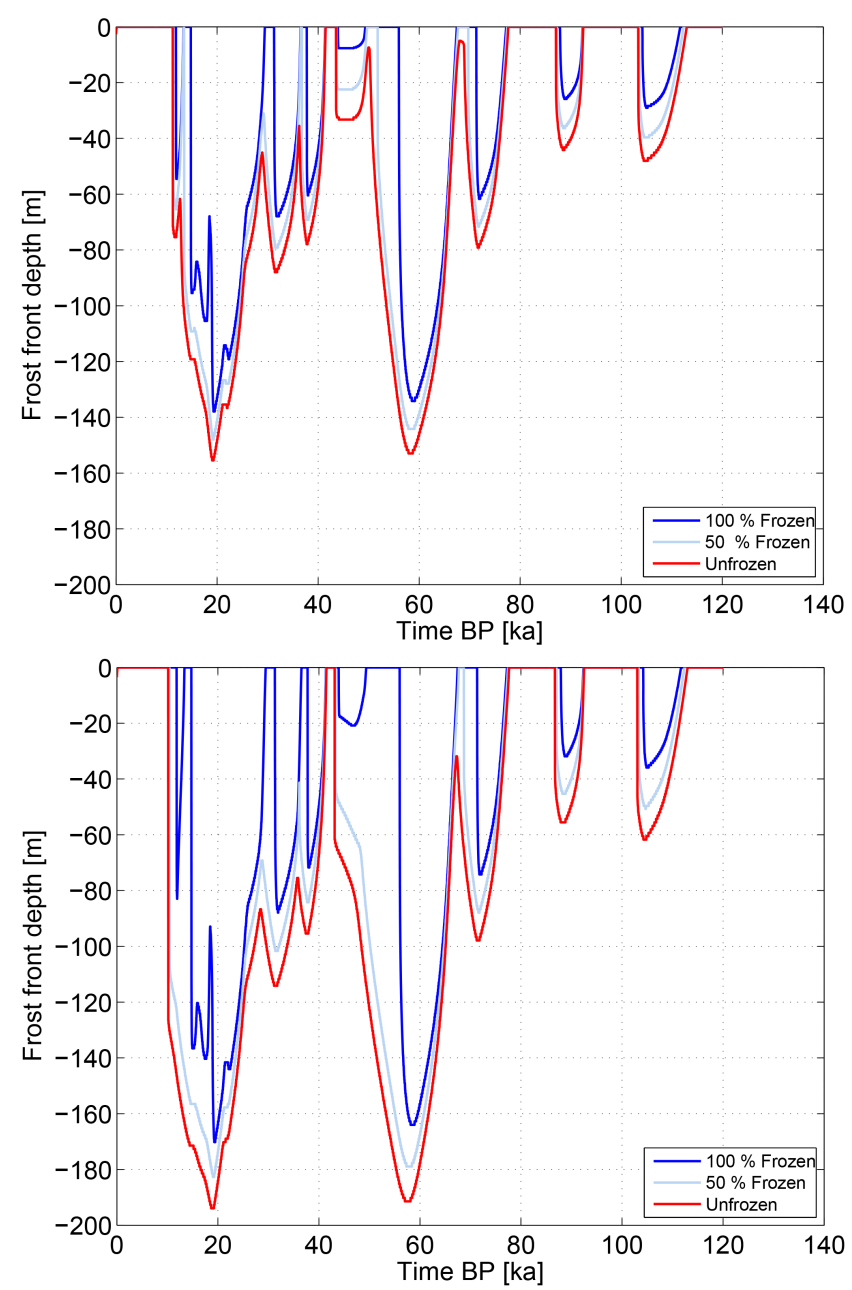

Figure 5. Top: best estimate permafrost progradation during a simulation of the Weichselian glaciation cycle for the FRP polygon. Bottom: idem, for the LBH polygon. These two polygons (FRP and $\mathrm{LBH})$ are at the low and high end of the resulting permafrost depths respectively.

ble parameter space are evaluated at the same time. The most frequently used global techniques are implemented using Monte Carlo simulations and are therefore called samplingbased methods. Global SA with regression-based methods rests on the estimation of linear models between parameters and model output. For linear trends, linear relationship measures that work well are the Pearson correlation coefficient (CC), partial correlation coefficients (PCCs) and standardized regression coefficients (SRC; Helton, 2005). In this study, the SRC will be used.

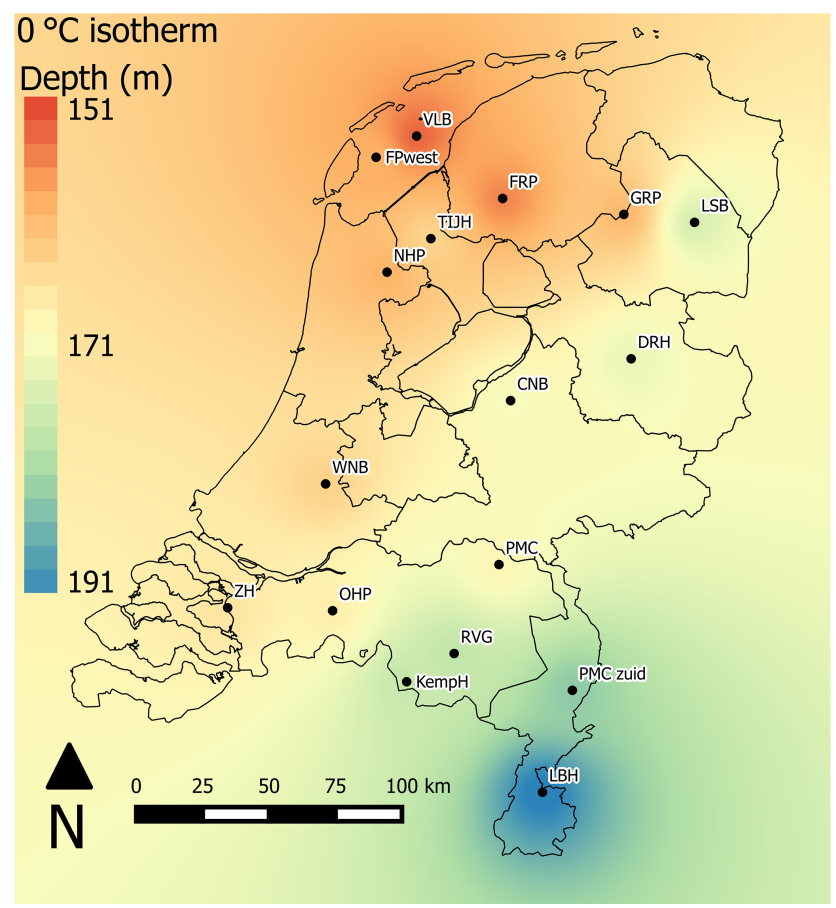

Figure 6. Interpolated best estimate maximum permafrost depth map for the $0^{\circ} \mathrm{C}$ isotherm. The pore water is assumed to be completely in the liquid phase.

\section{Results}

\subsection{Permafrost development during a Weichselian temperature cycle - reference case}

The definition of permafrost applied here is ground that remains at or below $0^{\circ} \mathrm{C}$ for at least 2 consecutive years (French, 2007). The $0^{\circ} \mathrm{C}$ isotherm is chosen as a conservative estimate of the permafrost front as explained earlier. Due to the choice of a gradual phase change between 0 and $-0.5^{\circ} \mathrm{C}$, a soil at $-0.25^{\circ} \mathrm{C}$ corresponds to a mixture of 50 water and $50 \%$ ice.

The progradation fronts (i.e. the location where the temperature reaches $0,-0.25$ and $-0.5^{\circ} \mathrm{C}$, and corresponding with 0,50 and $100 \%$ frozen soil respectively) for the FRP and LBH polygons are shown as a function of time (Fig. 5). The permafrost front penetrates about 155 to $195 \mathrm{~m}$ into the subsoil depending on the location, as a result of extremely low mean annual air temperatures during the final phase of MIS4 (early Pleniglacial) and the middle part of MIS2 (late Pleniglacial).

The spatial distribution of maximum permafrost depth at any time during a Weichselian climatic analogue is given in Fig. 6. The map is interpolated (inverse distance weighted) from individual polygon results, and is the result of model forcing by the best estimate climate evolution given in Fig. 3 . The maximum permafrost depth generally corresponds with the coldest peak in MIS2 (around $20 \mathrm{ka} \mathrm{BP}$ ). The depth of 


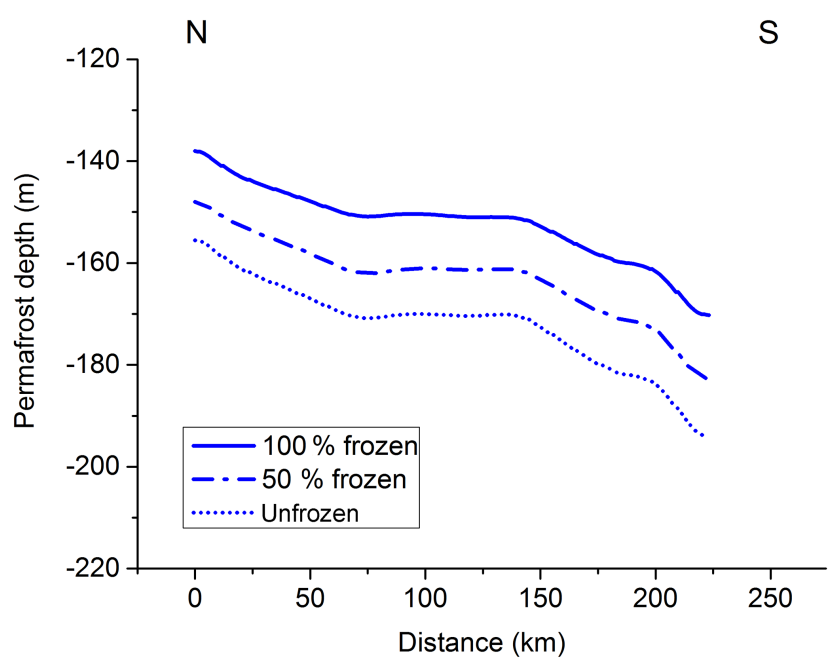

Figure 7. Simulated depth for different freezing states along a N-S transect from polygon centre FRP in the north to LBH in the south. See Fig. 1 for location of the profile.

the location where $0{ }^{\circ} \mathrm{C}$ is reached ranges from 155 to $195 \mathrm{~m}$. The spatial variability in permafrost depth is further illustrated along a N-S transect, from polygon centre FRP (Friesland Platform) in the north to LBH (Limburg High) in the south (Fig. 7).

Somewhat surprisingly, the calculated permafrost depth would be about $40 \mathrm{~m}$ less in the north. Intuitively, one would expect permafrost to reach greater depths in the north, because of the inferred temperature gradient over the country. As stated above, the forcing temperature was assumed to be spatially homogeneous for a given time step across the study area, such that the results can be interpreted solely in terms of subsurface properties. The spatial pattern of maximum permafrost depth is in fair agreement with the pattern of geothermal heat flux, as shown in Fig. 2, and a relationship with the weight fraction of sand can be observed as well. This seems logical since a higher geothermal heat flux imposes a stronger resistance against the intrusion of subzero temperatures into the soil. A higher sand fraction facilitates permafrost growth, as a sand matrix has a higher thermal conductivity, which allows a more rapid extraction of thermal energy towards the surface during cold periods. Thus, assuming a constant temperature evolution over the Netherlands, geothermal heat fluxes, and to a lesser extent sand percentage, seem to be the determining factor in explaining the $\mathrm{N}-\mathrm{S}$ variability of the maximum permafrost depth. Parameter sensitivity will be addressed in more detail in the section on the sensitivity analysis.

\subsection{Results of the uncertainty analysis}

The uncertainty analysis translates the uncertainty on the input parameters into an uncertainty on the permafrost depth $\left(0^{\circ} \mathrm{C}\right.$ isotherm). The results are shown in Fig. 8. The me-

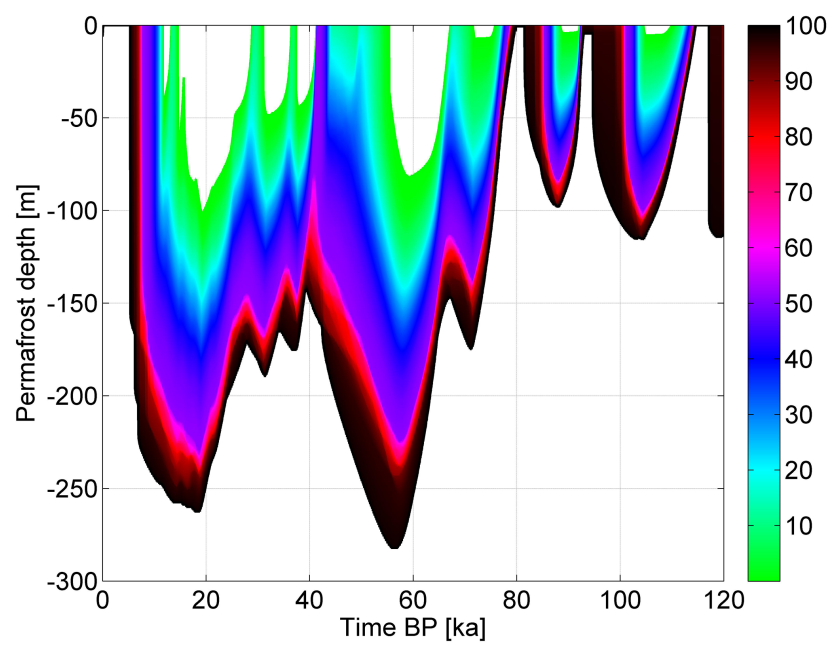

Figure 8. All percentiles of permafrost front penetration depth during a stochastic nationwide simulation of the Weichselian glaciation.

dian values of the maximum permafrost depth at a time of $20 \mathrm{ka}$ are about $150 \mathrm{~m}$, while the most conservative parameter combinations result in permafrost fronts going as deep as $280 \mathrm{~m}$. Note that maximum permafrost depth for the 95-100 percentiles occurs after the thermal minimum for the cold phase around $60 \mathrm{ka} \mathrm{BP}$, and not during the LGM (20 ka BP). This is caused by a number of simulations in which the random combination of cold temperatures in the period of 80 to $60 \mathrm{ka} \mathrm{BP}$ results in a very long and continuously cold period with temperatures ranging from -4 to $-11^{\circ} \mathrm{C}$. The difference between the $5 \%$ and $95 \%$ percentiles $(2 \sigma)$ is about $80 \mathrm{~m}$, which is quite high given the relatively low number of parameters.

\subsection{Results of the sensitivity analysis}

The goal of this sensitivity analysis (SA) is to determine the relationships between the uncertainty in output and the uncertainty in individual input parameters. SA identifies the parameters for which the greatest reduction in uncertainty or variation in model output can be obtained if the correct value of this parameter could be determined more precisely. The results are analysed by looking at the evolution of the SRC and PCC coefficients. PCC and SRC provide related, but not identical, measures of the variable importance. If input factors are independent, PCC and SRC give the same ranking of variable importance. This is the case in the present study, and we will focus on the SRC to discuss the sensitivity analysis. A positive correlation coefficient (SRC and/or PCC) means that a higher value of the parameter will cause a larger permafrost depth and vice versa.

It can be seen in Fig. 9 that the $R^{2}$ values are close to 1 , which indicates that the regression model is accounting 

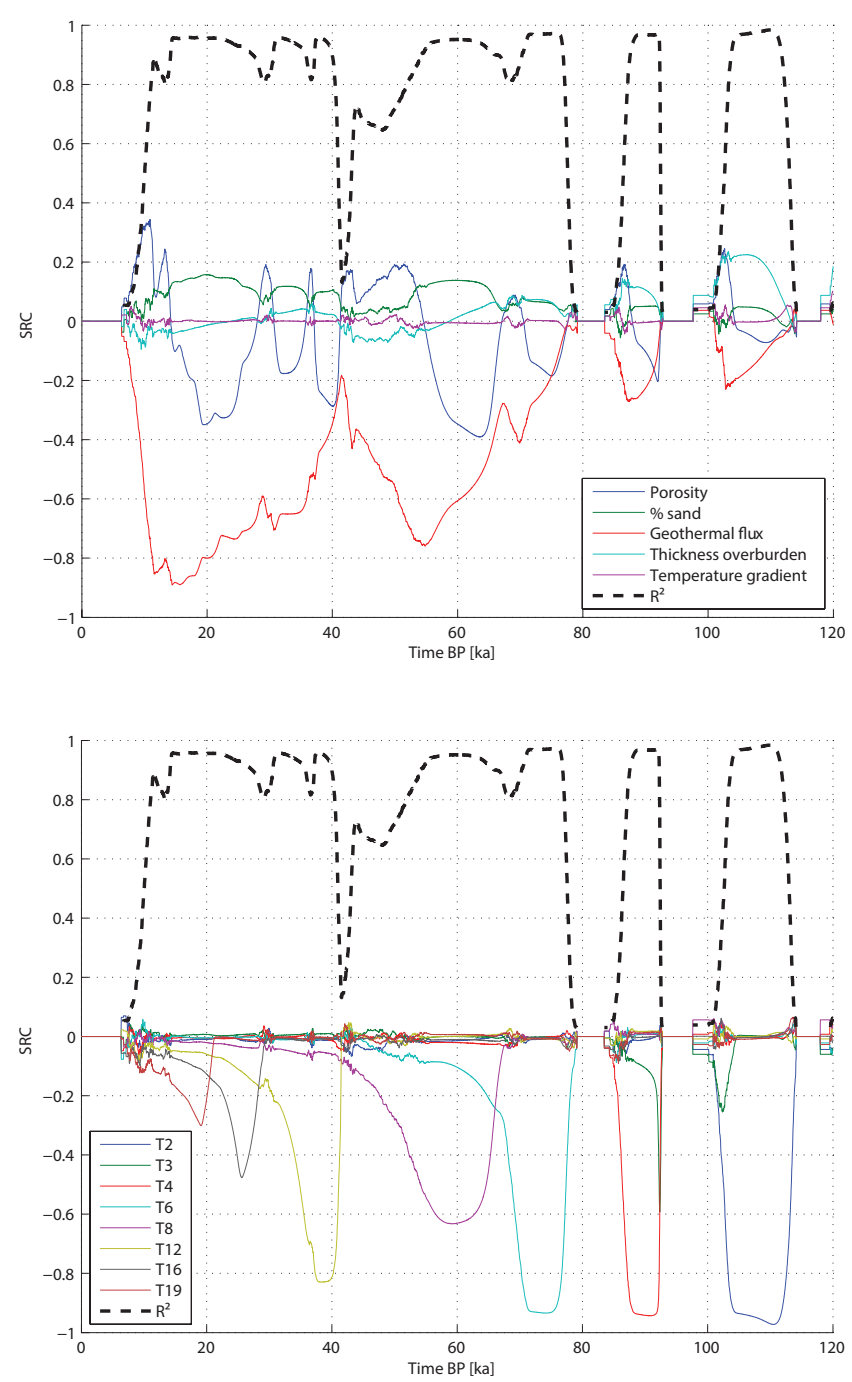

Figure 9. SRCs as a function of time for a global sensitivity study of permafrost progradation during a Weichselian glaciation (top: physical parameters, bottom: selected set of temperature parameters T1 to T26, which are variables that are used to control the magnitude of the various temperature plateaus during the Weichselian temperature cycle).

for most of the uncertainty in the permafrost depth, and the model is behaving in a linear way.

The SRC indicates that the geothermal heat flux is the most important parameter, aside from temperature forcing. It is interesting to note that during permafrost growth (e.g. around $90 \mathrm{ka}$ ) the geothermal heat flux is equally as important as the porosity. However, when the surface temperature again rises and the permafrost starts to degrade, the geothermal heat flux acts as the main driving force of the thawing process at the base of the permafrost, resulting in a decrease of the permafrost depth.

During the course of simulation time, correlation coefficients can change their sign. During permafrost growth, at the initial phase of a subzero temperature period, a higher porosity will hamper permafrost growth. Because of the larger effective heat capacity, a larger pore water content means that a larger amount of energy needs to be removed from the subsoil in order to cool it down and to induce a phase change of the total amount of pore water. A larger water content also decreases the total effective thermal conductivity, which slows down the extraction of thermal energy towards the surface. Thereafter, during the subsequent warmer period, a higher ice content will require a larger amount of heat to be supplied to thaw the permafrost.

The sand fraction shows a relatively strong, positive influence on permafrost depth, which confirms the findings of the nationwide simulation. Compared to clay, sand has a higher thermal conductivity, which will cause a more rapid cooling of the subsurface during cold periods.

The overburden thickness only seems to play a role during moderately cold periods (e.g. MIS $5 \mathrm{~b}$ and $5 \mathrm{~d}$ ). If the overburden thickness is lower than $500 \mathrm{~m}$, the remaining part of the domain is repleted with Boom Clay type material, which has a slightly lower thermal conductivity than the often sandy overburden, which slows down permafrost formation. This only seems to be of any importance in periods when the surface temperature is only slightly below the freezing point. Later, when the cold periods become more extreme (e.g. MIS 2 ), the difference in thermal conductivity at the clay-sand interface plays a less prominent role, and the other parameters become more significant.

Finally, it is no surprise that, being the driving force in the formation of a permafrost, the surface temperature is crucial at the time it is imposed on the computational domain (Fig. 9; in order not to overcrowd the figure, only 8 of the 26 temperature variables are shown). It is important to note that a specific correlation coefficient becomes larger when that temperature is maintained for a longer period (e.g. T2 and T4). Closer to the present, the dynamics of the temperature evolution during the Weichselian are better captured in the proxy data, which translates itself to a more detailed temperature evolution during the last $50 \mathrm{ky}$ (T12-T26). Subsequently, this makes the individual temperature parameters seem less important compared to the earlier temperatures, which can be seen as an artefact induced by the dynamics of the temperature curve.

Another interesting point to note is the fact that a low temperature during an early time frame can still manifest its influence thousands of years later. For instance, the SRC curves of T6 and T7 show a long tailing that still impacts the formation of the permafrost around $60 \mathrm{ka}$. This can be explained by the thermal inertia of the frozen soil, which has not been fully reverted to the initial temperatures at the start of a subsequent cold period (see also ter Voorde et al., 2014). 


\section{Discussion}

The best estimate permafrost depth values of $155-195 \mathrm{~m}$ $\left(0{ }^{\circ} \mathrm{C}\right.$ isotherm) calculated here for the Weichselian glaciation in the Netherlands are somewhat lower than the $200 \mathrm{~m}$ that was obtained by Govaerts et al. (2011) using the same model and the same temperature curve. In the latter study, a lower porosity was used (down to $30 \%$ ), which favours the development of permafrost and thus explains the deeper permafrost. We now compare the results to other permafrost depth modelling results for NW Europe during the Weichselian or a future analogue from Delisle (1998), Grassmann et al. (2010), Hartikainen et al. (2010), Holmén et al. (2011), Kitover et al. (2013) and Busby et al. (2015). These different modelling exercises revealed quite contrasting permafrost depths for the LGM, which is not surprising given that different approaches and parameter values were used with respect to palaeotemperatures, duration of cold phases, subsoil thermal properties, porosity, heat flux, ice advance, etc. The values derived from the different studies range between ca. 100 and ca. $300 \mathrm{~m}$ for a western European context, being site- or non-site specific. Kitover et al. (2013) used an extended cold period of unknown duration and a MAAT of $-8^{\circ} \mathrm{C}$ to produce steady-state continuous permafrost reaching $300 \mathrm{~m}$ depth. Holmén et al. (2011) calculated a median permafrost depth for northwestern France of ca. $120 \mathrm{~m}$ using a MAAT of $-6^{\circ} \mathrm{C}$ for the coldest peak during a future Weichselian analogue. The value of $100 \mathrm{~m}$ from Delisle et al. (1998) is based on a relatively high MAAT of $-7^{\circ} \mathrm{C}$ for the LGM during a very small time period at around $18 \mathrm{ka}$. Furthermore, that study used a fairly high geothermal heat flux, $60 \mathrm{~mW} \mathrm{~m}^{-3}$, as is the case for the study by Govaerts et al. (2011). The latter however used a lower MAAT $\left(-9^{\circ} \mathrm{C}\right)$ for the LGM, persisting for 2000 years and preceded by already very cold temperatures in the millennia before. Similar permafrost depths were obtained in the study by Grassman et al. (2010) for northern Germany covering the last $1 \mathrm{My}$. The maximum depth of $300 \mathrm{~m}$ for the permafrost base was realized during a cold peak around $400-450 \mathrm{ka}$ with a mean annual ground surface temperature of $-10^{\circ} \mathrm{C}$ and a heat flux of $50 \mathrm{~mW} \mathrm{~m}^{-2}$. Busby et al. (2015) calculated that for an extreme cold climate, based on the last glacial-interglacial cycle in Great Britain, maximum permafrost would vary between $180 \mathrm{~m}$ (South Midlands) and $305 \mathrm{~m}$ (Southern Uplands). The largest value of $305 \mathrm{~m}$ was obtained using an MAAT of ca. $-20^{\circ} \mathrm{C}$ for the coldest peak, which is about $8^{\circ} \mathrm{C}$ lower than the one used in the present study. Note that in the coldest Southern Uplands scenario ice-sheet advance was considered during the glacial cycle, which has a shielding effect on atmosphere-soil coupling. However, as only ground temperature was modelled by Busby et al. (2015), they could not make any statements about ice formation or the depth that partially or completely frozen ground might penetrate. Hartikainen et al. (2010) also defined several permafrost cases with maximum modelled permafrost depths $\left(0^{\circ} \mathrm{C}\right.$ isotherm $)$ of 260 and $390 \mathrm{~m}$ respectively for the Forsmark site in Sweden.

The stochastic approach applied in this study combines a large range of parameter values and boundary conditions. Interestingly, this results in a permafrost depth distribution ranging between 100 and $270 \mathrm{~m}$ for the LGM. This window seems to cover any of the calculated permafrost depths mentioned by previous studies. Some extreme values for the British Isles and Sweden that go beyond the thickest permafrost calculated in the present study are basically caused by much lower MAAT values for the coldest glacial peaks. Indeed, some of the remaining uncertainties are the duration and minimum MAAT values adopted for these cold peaks. Temperature reconstructions, based on periglacial deformation phenomena, show that the MAAT during the LGM in the Netherlands would have been equal to or lower than $-8^{\circ} \mathrm{C}$. In our coldest scenario, we adopted a value of $-11^{\circ} \mathrm{C}$ that would last for about 2000 years. To some extent these minimum scenario values remain somewhat arbitrary, and the question is how much they should be lowered in order to cover any possible future glacial scenario. Notwithstanding these remaining uncertainties, so far the $300 \mathrm{~m}$ depth may be regarded as a maximum value because the model is conservative with respect to vegetation and snow cover, groundwater flow and the depth of the unsaturated zone. These contributing factors would all push permafrost towards shallower depths. Note that in the OPERA-project the long term safety of a generic repository in the Boom Clay at a generic depth of $500 \mathrm{~m}$ will be assessed (Verhoef and Schröder, 2011). Future research should focus on defining an absolute minimum value for the MAAT used in permafrost calculations. It is also noted that the geothermal gradient, as used here for geothermal heat flux calculation, might not be in equilibrium yet with present-day climatic conditions (ter Voorde et al., 2014). This should be taken into account in future permafrost modelling work.

\section{Conclusions}

Permafrost depth modelling using a best estimate temperature curve of the Weichselian as an analogue for the future indicates that the permafrost front $\left(0{ }^{\circ} \mathrm{C}\right.$ isotherm) would indicate permafrost depths between $155-195 \mathrm{~m}$ in the Netherlands. Using the same climatic data for the entire country, the deepest permafrost is expected in the south, due to the lower geothermal heat flux and higher average sand content of the post-Rupelian overburden. Taking into account various sources of uncertainty, such as type and impact of vegetation, snow, air surface temperate gradients across the country, possible discrepancies in palaeoclimate reconstructions, porosity, lithology and geothermal heat flux, stochastic calculations point out that permafrost depth during the coldest stages of a glacial cycle such as the Weichselian, for any location in the Netherlands, would be between 130 
and $210 \mathrm{~m}$ at the $2 \sigma$ level. In any case, permafrost would not reach depths greater than $280 \mathrm{~m}$. The most sensitive parameters in permafrost development are the mean annual air temperatures and porosity, while the geothermal heat flux is the crucial parameter in permafrost degradation once temperatures start rising again. The permafrost depth distribution presented here encompasses many of the previously calculated values for other contexts. Furthermore, the uncertainty analysis in which a wide range of parameter values are considered makes the results presented here directly relevant for any western European lowland location with a sedimentary overburden.

The calculations presented here are robust and conservative.

\section{Data availability}

Input data can be accessed at http://bit.ly/2fjtYxP.

Acknowledgements. The present work has been funded by COVRA, the Dutch Central Organisation for Radioactive Waste. The findings and conclusions in this paper are those of the authors and do not necessarily represent the official position of COVRA. We thank the co-editor-in-chief Stephan Gruber for the critical review of the originally submitted paper. We also want to express our gratitude to Daniella Kitover and the anonymous reviewer for their helpful suggestions and comments on the discussion paper.

Edited by: S. Gruber

Reviewed by: D. Kitover and one anonymous referee

\section{References}

Annan, J. D. and Hargreaves, J. C.: A new global reconstruction of temperature changes at the Last Glacial Maximum, Clim. Past, 9, 367-376, doi:10.5194/cp-9-367-2013, 2013.

Bense, V. F., Ferguson, G., and Kooi, H.: Evolution of shallow groundwater flow systems in areas of degrading permafrost, Geophys. Res. Lett., 36, TL22401, doi:10.1029/2009GL039225, 2009.

Berger, A. and Loutre, M. F.: An Exceptionally Long Interglacial Ahead?, Science, 297, 1287-1288, 2002.

Beerten, K., De Craen, M., and Leterme, B.: Long-term evolution of the surface environment of the Campine area, northeastern Belgium: first assessment, in: Clays in Natural and Engineered Barriers for Radioactive Waste Confinement, edited by: Norris, S., Bruno, J., Cathelineau, M., Delage, P., Fairhurst, C., Gaucher, E. C., Höhn, E. H., Kalinichev, A., Lalieux, P., and Sellin, P., Geological Society, London, Special Publications, 400, 33-51, 2014.

BIOCLIM Deliverable D3: Global climatic features over the next million years and recommendation for specific situations to be considered, Modelling Sequential Biosphere Systems under Climate Change for Radioactive Waste Disposal, A project within the European Commission 5th Euratom Framework Programme Contract FIKW-CT-2000-00024s, available at: http://www.andra.fr/bioclim/documentation.htm (last access: 20 February 2016), 2001.
Bolado, R., Badea A., and Poole, M.: Review of expert judgment methods for assigning PDFs, EC-PAMIINA M 2.2.A.3, 2009.

Busby, J. B., Lee J. R., Kender S., Williamson J. P., and Norris S.: Modelling the potential for permafrost development on a radioactive waste geological disposal facility in Great Britain, Proceedings of the Geologists' Association, 126, 664-674, 2015.

Busschers, F. S., Kasse, C., van Balen, R. T., Vandenberghe, J., Cohen, K. M., Weerts, H. J. T., Wallinga, J., Johns, C., Cleveringa, P., and Bunnik, F. P. M.: Late Pleistocene evolution of the Rhine-Meuse system in the southern North Sea basin: imprints of climate change, sea-level oscillation and glacio-isostacy, Quaternary Sci. Rev., 26, 3216-3248, 2007.

Buylaert, J. P., Ghysels, G., Murray, A. S., Thomsen, K. J., Vandenberghe, D., De Corte, F., Heyse, I., and Van den haute, P.: Optical dating of relict sand wedges and composite-wedge pseudomorphs in Flanders, Belgium, Boreas, 38, 160-175, 2008.

Chen, G., Sillen, X., Verstricht, J., and Li, X.: Revisiting a simple in situ heater test: the third life of ATLAS, Clays in Natural and Engineered Barriers for Radioactive Waste Confinement, Nantes, France, 29 March-1 April, 2010.

COMSOL: COMSOL Multiphysics 3.5a, Earth Science Module, COMSOL AB, Stockholm, Sweden, 2008.

Delisle, G.: Numerical simulation of permafrost growth and decay, J. Quaternary Sci., 13, 325-333, 2008.

French, H. M.: The Periglacial Environment, Wiley ISBN 0470865903, 2007.

Govaerts, J., Weetjens, E., and Beerten, K.: Numerical simulation of permafrost depth at the Mol site, External Report SCK CENER-148, 2011.

Grassmann, S., Cramer, B., Delisle, G., Hantschel, T., Messner, J., and Winsemann, J.: pT-effects of Pleistocene glacial periods on permafrost, gas hydrate stability zones and reservoir of the Mittelplate oil field, northern Germany, Mar. Petrol. Geol., 27, 298306, 2010.

Grupa, J. B.: Stand van zaken van internationaal onderzoek naar opslag en eindberging, NRG 23498/14.128247, 2014.

Guiot, J., Pons, A., De Beaulieu and J. L., and Reille, M.: A 140000 -year continental climate reconstruction from two European pollen records, Nature, 338, 309-313, 1989.

Gunnink, J. L., Maljers, D., van Gessel, S. F., Menkovic, A., and Hummelman, H. J.: Digital Geological Model (DGM): a 3D raster model of the subsurface of the Netherlands, Neth. J. Geosci., 92, 33-46, 2013.

Hartikainen, J., Kouhia, R., and Wallroth, T.: Permafrost Simulations at Forsmark using a Numerical 2-D Thermo-HydroChemical Model, Svensk Karnbranslehantering AB SKB TR-0917, 2010.

Helton, J. C.: Uncertainty and sensitivity analysis techniques for use in performance assessment for radioactive-waste disposal, Reliab. Eng. Syst. Saf., 42, 327-367, 1993.

Helton J. C., Davis, F. J., and Johnson, J. D.: A comparison of uncertainty and sensitivity analysis results obtained with random and Latin hypercube sampling, Reliab. Eng. Syst. Safe., 89, 305-330, 2005.

Holmén, J., Benabderrahmane, H., Buoro, A., and Brulhet, J.: Modelling of Permafrost Freezing and Melting and the Impact of a Climatic Cycle on Groundwater Flow at the Meuse/Haute-Marne Site, Phys. Chem. Earth, 36, 1531-1538, 2011. 
Huijzer, B. and Vandenberghe, J.: Climatic reconstruction of the Weichselian Pleniglacial in northwestern and central Europe, J. Quaternary Sci., 13, 391-417, 1998.

Kitover, D. T., van Balen, R. T., Roche, D. M., Vandenberghe, J., and Renssen, H.: New Estimates of Permafrost Evolution during the Last $21 \mathrm{k}$ Years in Eurasia using Numerical Modelling, Periglacial Processes and Landforms, 24, 286-303, 2013.

Kömle, N. I., Bing, H., Feng, W. J., Wawrzaszek, R., Hütter, E. S., He Ping, Marczewski, W., Dabrowski, B., Schröer, K., and Spohn, T.: Thermal conductivity measurements of road construction materials in frozen and unfrozen state, Acta Geotechnica, 2, 127-138, 2007.

Kooi, H., Johnston, P., Lambeck, K., Smither, C., and Molendijk, R.: Geological causes of recent $(\sim 100 \mathrm{yr})$ vertical land movement in the Netherlands, Tectonophysics, 299, 297-316, 1998.

Kurylyk, B., MacQuarrie, K., and Voss, C.: Climate change impacts on groundwater and soil temperatures in cold and temperate regions: Implications,mathematical theory, and emerging simulation tools, Earth Sci. Rev., 138, 313-334, 2014.

Lunardini, V. J.: Theory of $n$ factors and correlation of data. Proceedings of the 3rd International Conference on Permafrost, 10 13 July 1978, Edmonton, Alta, National Research Council of Canada, Ottawa, Ont., 1, 40-46, 1978.

Mallants, D.: Basic concepts of water flow, solute transport, and heat flow in soils and sediments, second edition, SCK CENBLG-991, 169-183, 2006.

Marino, S., Hogue, I. B., Ray, C. J., and Kirschner, D. E.: A methodology for performing global uncertainty and sensitivity analysis in systems biology, J. Theor. Biol., 254, 178-196, 2008.

Marivoet, J. and Bonne, A.: PAGIS, disposal in clay formations, SCK CEN-R-2748, 1988.

Marivoet, J., Beuth, T., Alonso, J., and Becker, D.-A.: Task reports for the first group of topics: Safety Functions, Definition and Assessment of Scenarios, Uncertainty Management and Uncertainty Analysis, Safety Indicators and Performance/Function Indicators, EC-PAMINA Del. 1.1.1, 2008.

Matlab: The MathWorks, http://www.mathworks.com/ (last access: 1 June 2016), 1993.

McCauley, C. A., White, D. M., Lilly, M. R., and Nyman, D. M.: A comparison of hydraulic conductivities, permeabilities and infiltration rates in frozen and unfrozen soils, Cold Reg. Sci. Technol., 34, 117-125, 2002

Mottaghy, D. and Rath, V.: Latent heat effects in subsurface heat transport modelling and their impact on palaeotemperature reconstructions, Int. J. Geophys., 164, 236-245, 2006.

NGRIP: North Greenland Ice Core Project members, North Greenland Ice Core Project members: High-resolution record of Northern Hemisphere climate extending into the last interglacial period, Nature, 431, 147-151, 2004.

Noetzli, J. and Gruber, S.: Transient thermal effects in Alpine permafrost, The Cryosphere, 3, 85-99, doi:10.5194/tc-3-85-2009, 2009.

Othman, M. A. and Benson, C. H.: Effect of freeze-thaw on the hydraulic conductivity and morphology of compacted clay, Can. Geotechn. J., 30, 236-246, 1993.

Renssen, H. and Vandenberghe, J.: Investigation of the relationship between permafrost distribution in NW Europe and extensive winter sea-ice cover in the North Atlantic Ocean during the cold phases of the Last Glaciation, Quaternary Sci. Rev. hydrogeo- logical and palaeoenvironmental data set for large-scale groundwater flow model simulations in the northeastern Netherlands, Meded. Rijks Geol. Dienst, 52, 105-134, 2003.

Roy, R. F., Beck, A. E., and Touloukian, Y. S.: Thermophysical properties of rocks, Physical Properties of Rocks and Minerals, 409-502, McGraw-Hill, New York, 1981.

Stocker, T. F., Qin, D., Plattner, G.-K., Alexander, L. V., Allen, S. K., Bindoff, N. L., Bréon, F.-M., Church, J. A., Cubasch, U., Emori, S., Forster, P., Friedlingstein, P., Gillett, N., Gregory, J. M., Hartmann, D. L., Jansen, E., Kirtman, B., Knutti, R., Krishna Kumar, K., Lemke, P., Marotzke, J., Masson-Delmotte, V., Meehl, G. A., Mokhov, I. I., Piao, S., Ramaswamy, V., Randall, D., Rhein, M., Rojas, M., Sabine, C., Shindell, D., Talley, L. D., Vaughan, D. G., and Xie, S.-P.: Technical Summary, in: Climate Change 2013: The Physical Science Basis, Contribution of Working Group I to the Fifth Assessment Report of the Intergovernmental Panel on Climate Change, edited by: Stocker, T. F., Qin, D., Plattner, G.-K., Tignor, M., Allen, S. K., Boschung, J., Nauels, A., Xia, Y., Bex, V., and Midgley, P. M., Cambridge University Press, Cambridge, United Kingdom and New York, NY, USA, 2013.

Stotler, R. L., Frape, S. K., Ruskeeniemi, T., Ahonen, L., Onstott, T. C., and Hobbs, M. Y.: Hydrogeochemistry of groundwaters in and below the base of thick permafrost at Lupin, Nunavut, Canada, J. Hydrol., 373, 80-95, 2009.

Svendsen, J. I., Alexanderson, H., Astakhov, V. I., Demidov, I., Dowdeswelle, J. A., Funder, S., Gataullin, V., Henriksen, M., Hjort, C., Houmark-Nielsen, M., Hubberten, H. W., Ingólfsson, Ó., Jakobsson, M., Kjær, K. H., Larsen, E., Lokrantz, H., Lunkka, J. P., Lyså, A., Mangerud, J., Matiouchkov, A., Murray, A., Möller, P., Niessen, F., Nikolskaya, O., Polyak, L., Saarnisto, M., Siegert, C., Siegert, M. J., Spielhagen, R. F., and Stein, R.: Late Quaternary ice sheet history of northern Eurasia, Quaternary Sci. Rev., 23, 1229-1272, 2004.

ter Voorde, M., van Balen, R., Luijendijk, E., and Kooi, H.: Weichselian and Holocene climate history reflected in temperatures in the upper crust of the Netherlands. Netherlands Journal of Geosciences, Geologie en Mijnbouw, 93, 107-117, doi:10.1017/njg.2014.9, 2014.

van Gijssel, K.: A hydrogeological and palaeoenvironmental data set for large-scale groundwater flow model simulations in the northeastern Netherlands, Meded. Rijks Geol. Dienst, 52, 105 134, 1995.

Vandenberghe, J. and Pissart, A.: Permafrost changes in Europe during the Last Glacial, Permafrost Perigl., 4, 121-135, 1993.

Vandenberghe, J., French, H. M., Gorbunov, A., Marchenko, S., Velichko, A. A., Jin, H., Cui, Z., Zhang, T., and Wan, X.: The Last Permafrost Maximum (LPM) map of the Northern Hemisphere: permafrost extent and mean annual air temperatures, 2517 ka BP, Boreas, 43, 652-666, doi:10.1111/bor.12070, 2014.

Vandenberghe, N. and Mertens, J.: Differentiating between tectonic and eustasy signals in the Rupelian Boom Clay cycles (Southern North Sea Basin), Newsletters on Stratigraphy, 46, 319-337, 2013.

Verhoef, E. and Schröder, T. J.: Research Plan, OPERA-PGCOV004, COVRA N.V., 2011.

Vernes, R. W. and van Doorn, T. H. M.: Van Gidslaag naar Hydrogeologische eenheid, Toelichting op de totstandkoming van de dataset REGIS II, TNO-rapport NITG 05-038-B, Nederlands 
Instituut voor Toegepaste Geowetenschappen TNO, Geological survey of the Netherlands, 66 pp., 2005.

Weert, F. H. A., van Gijssel, K., Leijnse, A., and Boulton, G. S.: The effects of Pleistocene glaciations on the geohydrological system of Northwestern Europe, J. Hydrol., 195, 137-159, 1997.
Wong, T. E., de Lugt, I. R., Kuhlmann, G., and Overeem, I.: Tertiary, in: Geology of the Netherlands, edited by: Wong, T. E., Batjes, D. A. J., and de Jager, J., Royal Netherlands Academy of Arts and Sciences, 151-171, 2007. 